\title{
The Power of Teamwork: Winning the 2007 Ergo Cup
}

Christine Naca
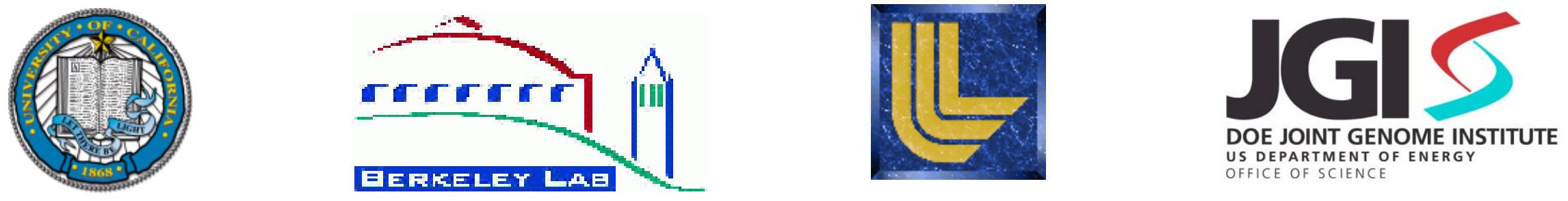


\section{Ov́erview}

- Description of the JGI

- Overview of Production Tasks

- Ergo Cup Competition

- JGI Ergonomics Program 


\section{DOE Joint Genome Institute}

- 250 Staff: $30 \%$ LLNL and $70 \%$ LBNL

- Mix of research and manufacturing work

-Integrated Safety Management (ISM)

- Stephen Franaszek (LBNL)

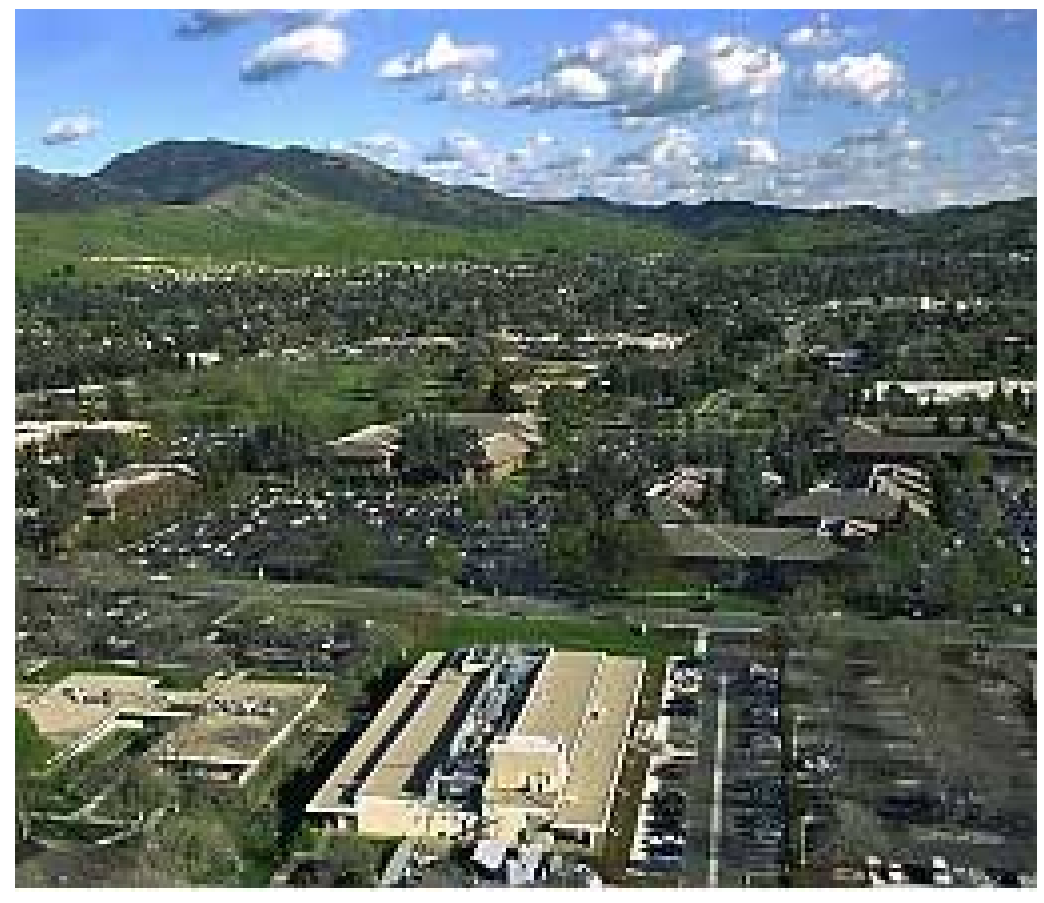

Walnut Creek, CA 


\section{Office \& Manufacturing Work Environments}

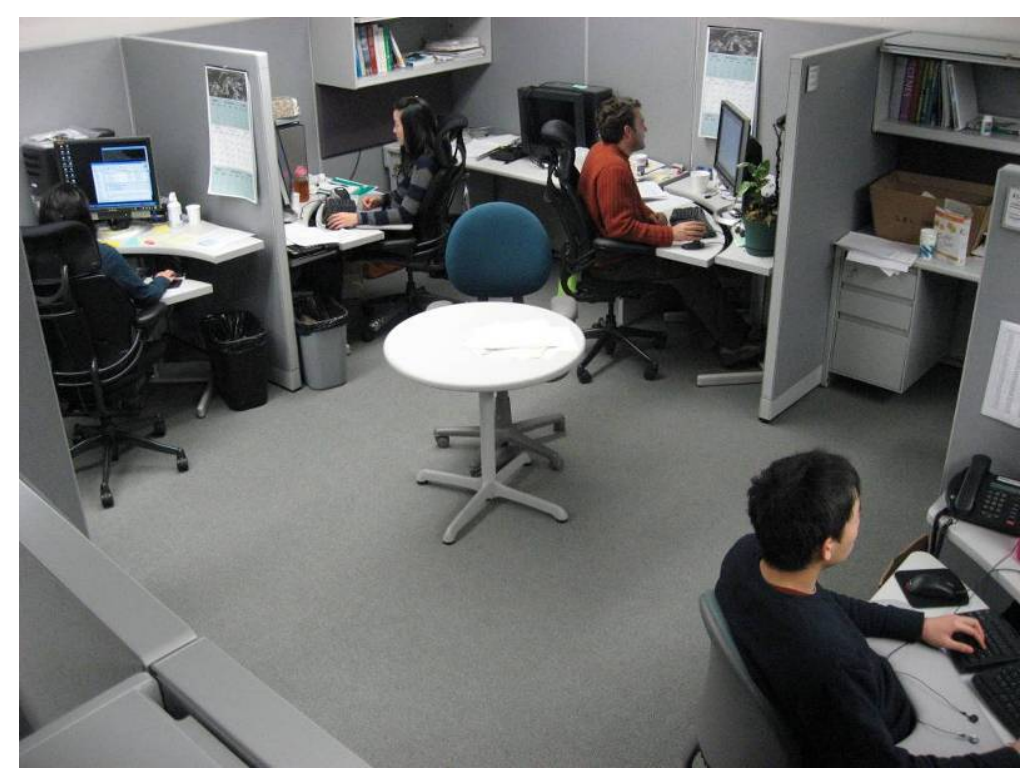

$60 \%$ staff in computerintensive office settings

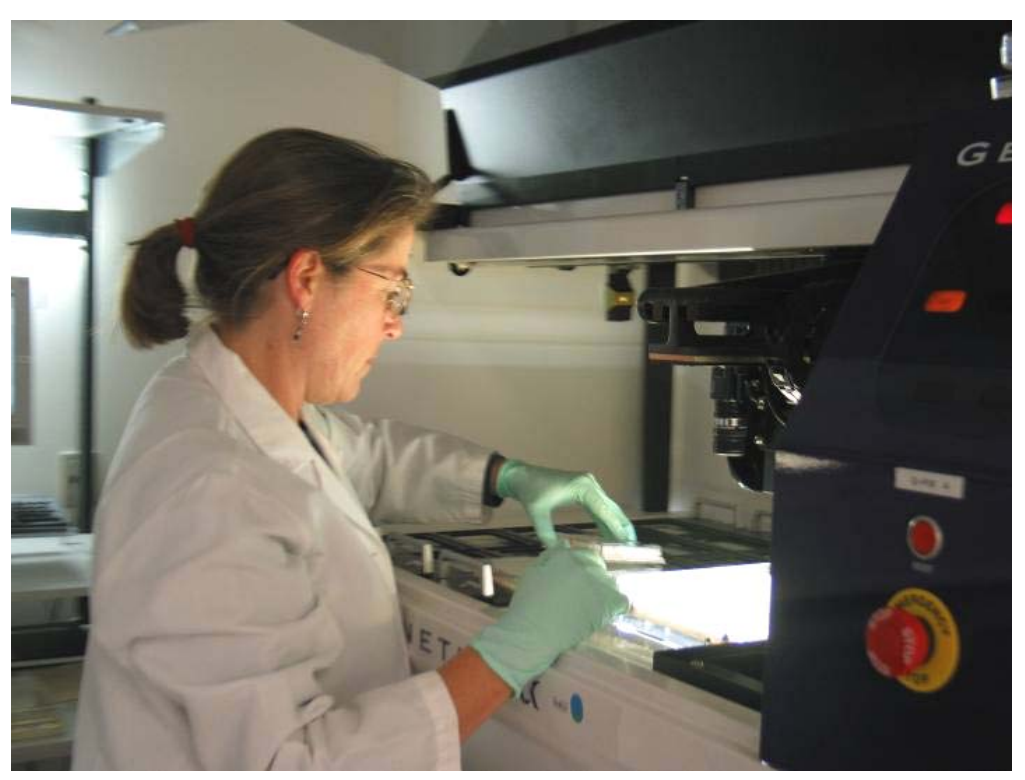

$40 \%$ staff in hand-intensive production tasks (2 shifts) 


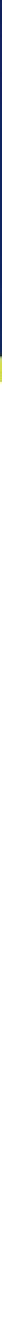

- $40 \%$ of the staff make up the manufacturing work environment

- High throughput laboratory manufacturing

- Hand-intensive repetitive tasks

- 32 people, 2 shifts/day 


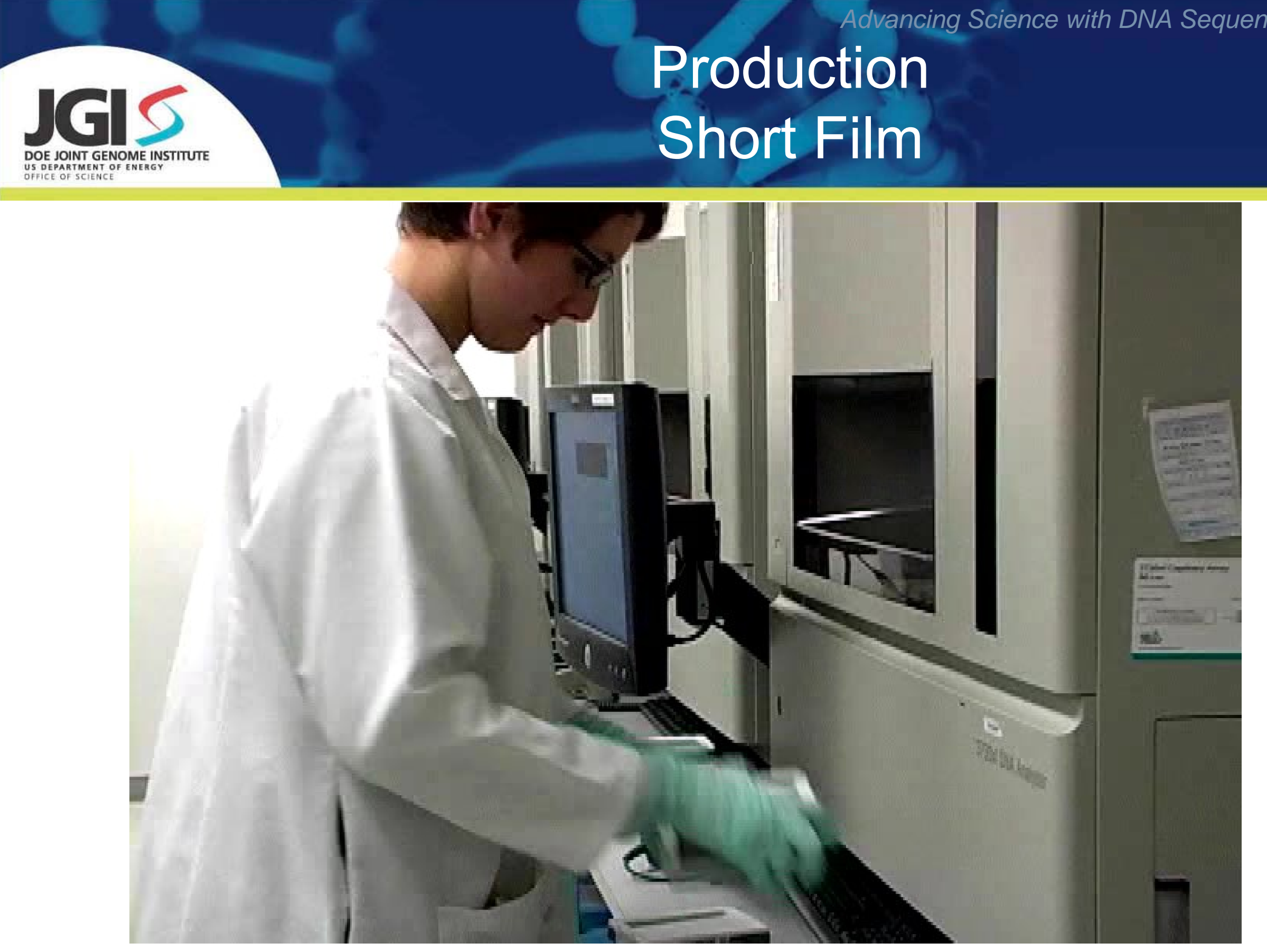




\section{Plating Process Details}

\section{Purpose of Plating:}

- To evenly spread individual bacteria onto agarose growth media.

- Bacteria grow into randomly spaced separate colonies that can then be picked, by robot, into microtiter plates.

- The result of the overall process is to put individual samples into individual sample wells. 


\section{Plating Process Details}

\section{Plating Process:}

- Pour glass beads onto bioassay plate.

- Pipette solution onto bioassay plate.

- Stack 4-5 plates together.

- Shake and tilt the plates until the beads evenly spread the solution across the agarose gel on the plate.

- Remove the glass beads

\section{Plating Stats:}

- 9"x9" bioassay plates

- Weight: $1.2 \mathrm{lbs} /$ plate (low profile) or $1.4 \mathrm{lbs} /$ plate (high profile)

- 40 plates/batch

- 4-5 plates/cycle

- 1-2 minute shake time/cycle

- Approx. 100 efforts/minute

- Total processing time 40 minutes 

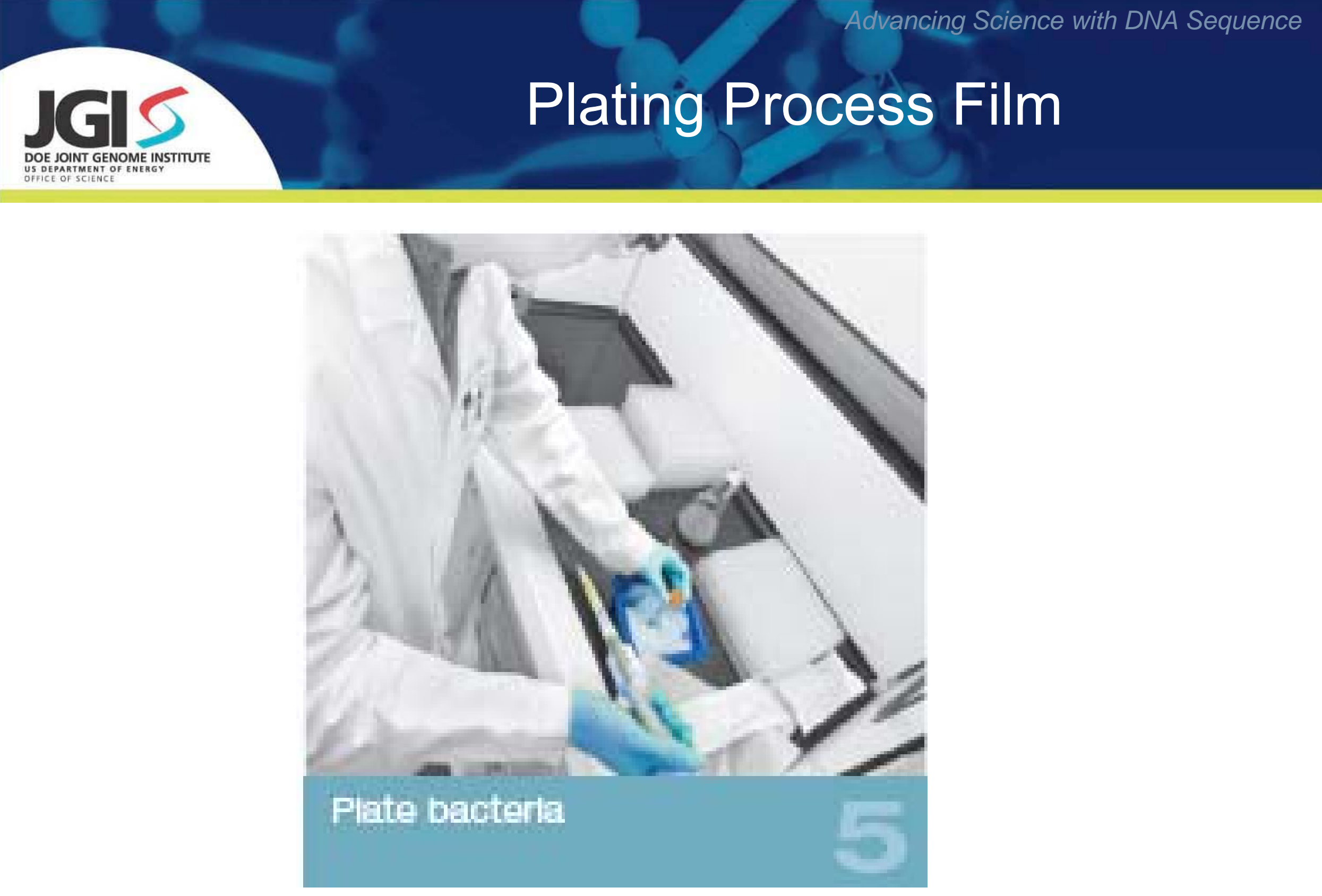


\section{Ergo Evaluation Techniques}

Semiquantitative Assessment Methods

Moore-Garg Strain Index

-Estimates the risk of injury to the distal upper extremity (elbow and below) -Integrates risk factors: force, repetition, posture, recovery time, and duration of the day 


\section{Moore-Garg Strain Index}

Job / Task: Plating, Manually with High Profile Bioassays

SI Score Interpretation

$<3 \quad$ Safe

Date: $12 / 13 / 2006$

Analyst: Christine Naca, Ira Janowitz

3-5 Uncertain

5-7 Some Risk

$=7$ Hazardous

Product of all multipliers

\begin{tabular}{|c|c|c|c|c|c|}
\hline & & & $S I=$ & 60.8 & \multirow[b]{2}{*}{$\%$ Max, MVC } \\
\hline Variable & Rating Criterion & Observation & $\begin{array}{c}\text { Variable } \\
\text { Multiplier }\end{array}$ & $\begin{array}{c}\text { Enter } \\
\text { Multiplier }\end{array}$ & \\
\hline \multirow{3}{*}{$\begin{array}{c}\text { Intensity of } \\
\text { Exertion }\end{array}$} & Light & Light: Barely noticeable or relaxed effort (BS: 0-2) & 1 & & $<25 \%$ \\
\hline & Somewhat Hard & Somewhat Hard: Noticeable or definite effort (BS: 3) & 3 & & $25-35 \%$ \\
\hline & Hard & Hard: Obvious effort; Unchanged facial expression (BS: 4-5) & 6 & & $35-55 \%$ \\
\hline (BS is Borg & Very Hard & Very Hard: Substantial effort; Changes expression (BS: 6-7) & 9 & 0 & $55-75 \%$ \\
\hline Scale) & Near Maximal & Near Maximal: Uses shoulder or trunk for force (BS: 8-10) & 13 & $\mathbf{y}$ & $>75 \%$ \\
\hline & $<10 \%$ & & 0.5 & & \\
\hline Duration of & $10-29 \%$ & & 1.0 & & \\
\hline Exertion (\% of & $30-49 \%$ & & 1.5 & & \\
\hline Cycle) & $50-79 \%$ & & 2.0 & & \\
\hline & $>80 \%$ & & 3.0 & 3.0 & \\
\hline & $<4$ & & 0.5 & & \\
\hline & $4-8$ & & 1.0 & & \\
\hline $\begin{array}{l}\text { Efforts Per } \\
\text { Minute }\end{array}$ & $9-14$ & & 1.5 & & groups of 5,40 total plates \\
\hline & $15-19$ & & 2.0 & & \\
\hline & $>20$ & & 3.0 & 3.0 & \\
\hline & Very Good & Perfectly Neutral & 1.0 & & \\
\hline Hand Muriot & Good & Near Neutral & 1.0 & & \\
\hline $\begin{array}{l}\text { Hand/Wist } \\
\text { Posture }\end{array}$ & Fair & Non-Neutral & 1.5 & & \\
\hline & Bad & Marked Deviation & 2.0 & 30 & \\
\hline & Very Bad & Near Extreme & 3.0 & 3.0 & \\
\hline & Very Slow & Extremely relaxed pace & 1.0 & & \\
\hline & Slow & Taking one's own time & 1.0 & & \\
\hline Speed of Work & Fair & Normal speed of motion & 1.0 & & \\
\hline & Fast & Rushed, but able to keep up & 1.5 & 10 & \\
\hline & Very Fast & Rushed and barely/unable to keep up & 2.0 & 1.0 & \\
\hline & $<1$ & & 0.25 & & \\
\hline & $1-2$ & & 0.50 & & \\
\hline $\begin{array}{l}\text { Duration of Task } \\
\text { Per Day (hours) }\end{array}$ & $2-4$ & & 0.75 & & \\
\hline & $4-8$ & & 1.00 & 0.25 & \\
\hline & $>8$ & & 1.50 & & \\
\hline
\end{tabular}

Note: This worksheet was adapted and interpreted

by the USF investigators. No warranty is offered.

Reference: J. Steven Moore \& Arun Garg, Thomas E. Bernard and Robert B. Walton

The Strain Index. A Proposed Method to University of South Florida

Analyze Jobs For Risk of Distal Upper College of Public Health

Extremity Disorders; Am. Ind. Hyg. Assoc. Tampa FL 33612-3805 (813) 974-6629

J. 56:443-458 (1995)

Partial support from

thernard@hsc.usf.edu and rwalton@hsc.

UAW-Ford NJCHS

thernard@och.usf.edu

Ford Motor Company

v2.2 1/11/01 @2001 Thomas E. Bernard

US Air Force

No Warranty: Expressed or Implied. 


\section{Manual Plating Process}

\section{Problem}

\section{Risk Factors:}

- High grip force when handling 5 plates/cycle

- Wide (4") grip span (low profile)

-Grip Force $30-41 \%$ of maximum voluntary contraction; MooreGarg Strain Index $=40.5$

\section{Musculoskeletal Problems:}

-Awkward hand and wrist postures to repeatedly tilt and rotate the plates for $40 \mathrm{~min} / \mathrm{batch}$

-Reports of discomfort and fatigue in operators in upper extremities, shoulders, and back.

\section{Workstation Layout:}

- Conducted at a fume hood in a high traffic walkway

-Does not accommodate a sitting workstation due to the lack of leg clearance.

\section{Efficiency:}

-4 plates per cycle manually, limited by weight (8-10lbs) \& awkward grip of plates
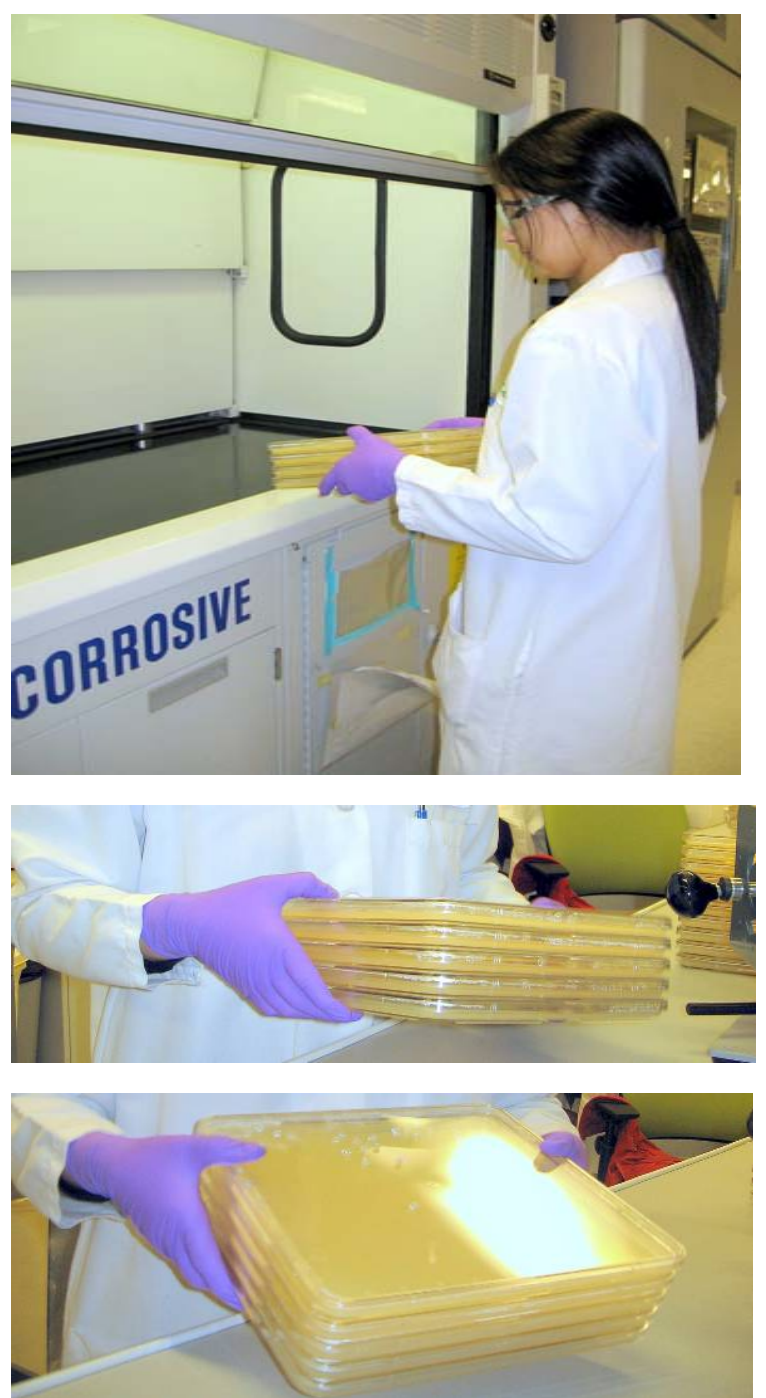


\section{SHAKE 'N PLATE}

\section{TEAM ERGONOMIC SOLUTION}
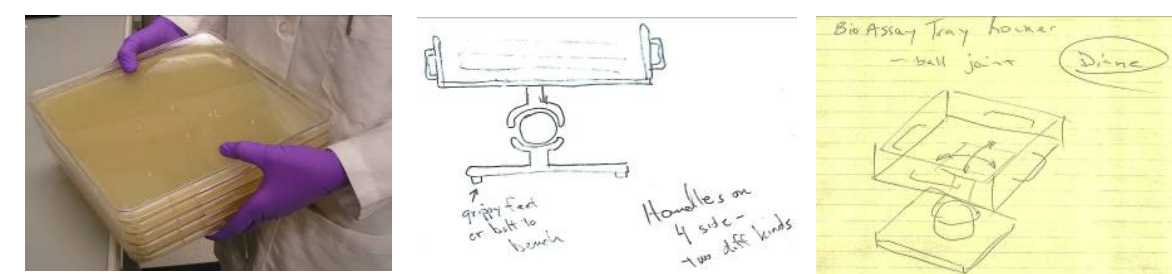

Hand-held

Manual process

Technologist

Sketch of

Solution

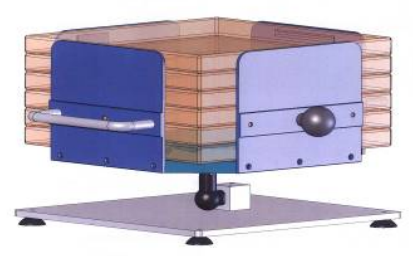

Mechanical

Engineering

Sketch of

Solution

Mechanical Engineering Technical Design

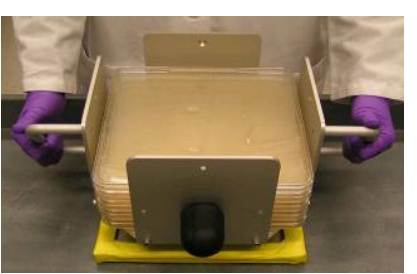

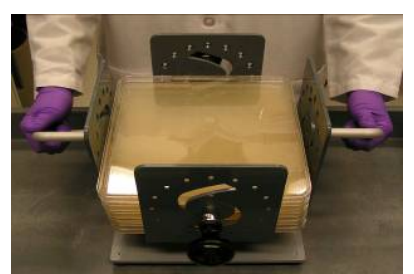

Initial

Engineering Prototype (too heavy)
Final Manual Tool

Solutions were initiated by production line operators' participation in process improvement. 


\section{SHAKE 'N PLATE}

\section{rame}

\section{Solution}

Intermediate Interventions:

-Lighter weight low-profile bioassay plates (reduced weight by $19 \%$ and grip span to $3 "$ )

-Risk factors still high (Strain Index dropped from 60.8 to 40.5).

\section{Workstation Layout:}

-Process was moved out of fume hood onto a lab bench (less foot traffic)

-Accommodates option of sit down or standing workstation (adequate leg clearance and better quality anti-fatigue mat)

\section{Tool:}

-Swiveling manual plating fixture with 3 degrees of freedom, eliminating the sustained gripping of the plates (dropped Strain Index to a 'safe' score of 2.3).

\section{Efficiency:}

-The acceleration, tilt, and rotation of the fixture are controlled by the operator. (Important for the glass beads to travel across entire plate in order to efficiently produce high quality bacterial colonies, critical for subsequent steps in the production process).
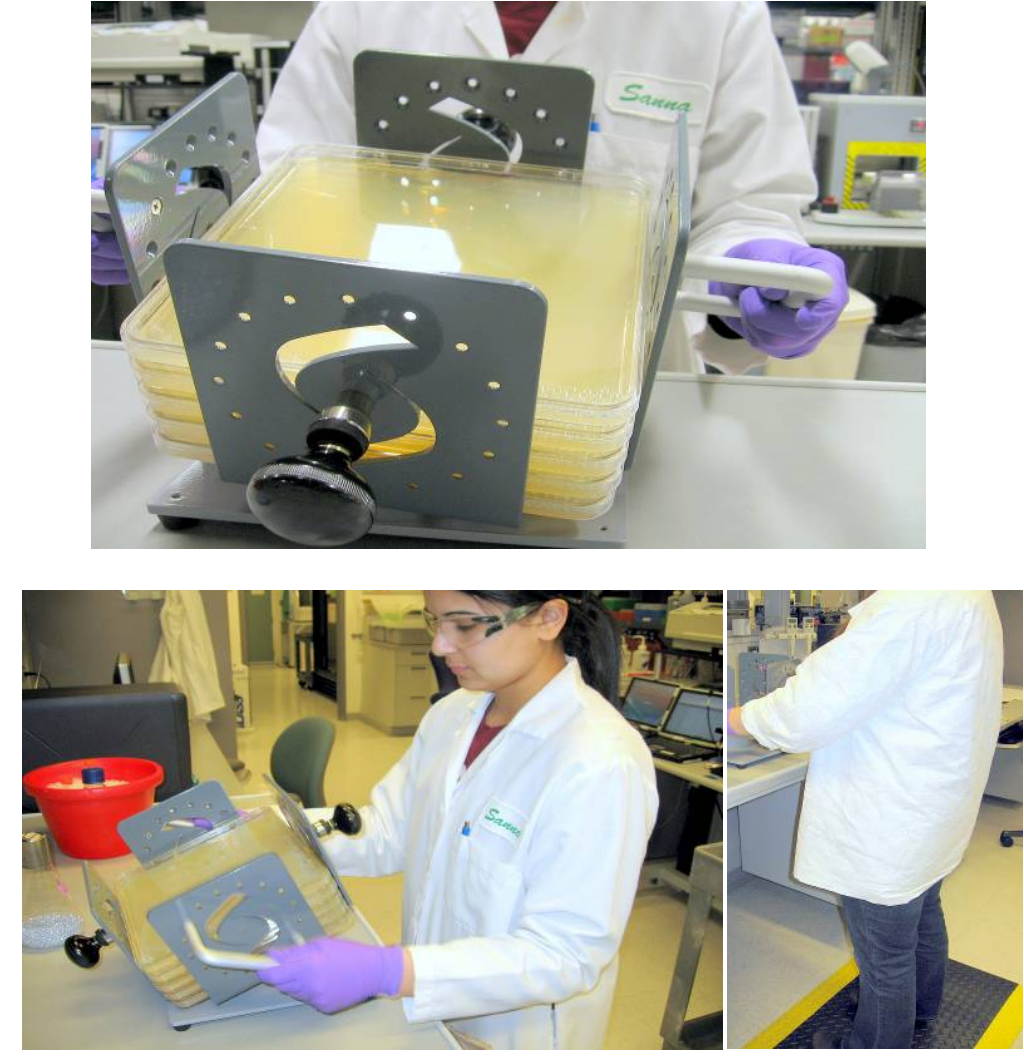


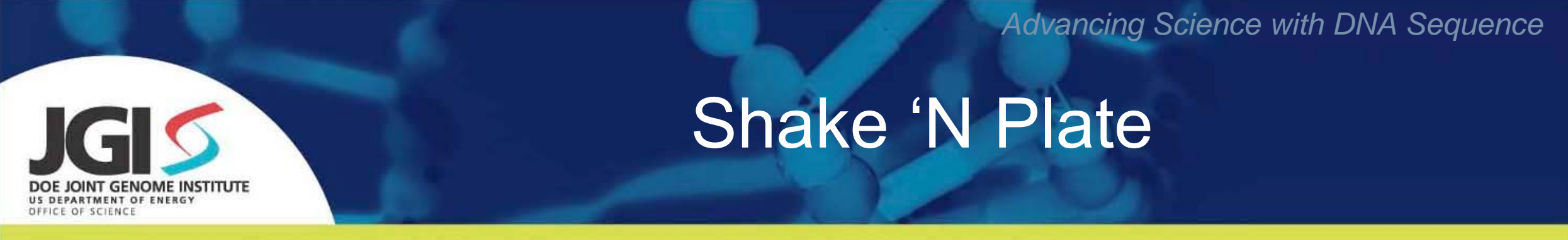

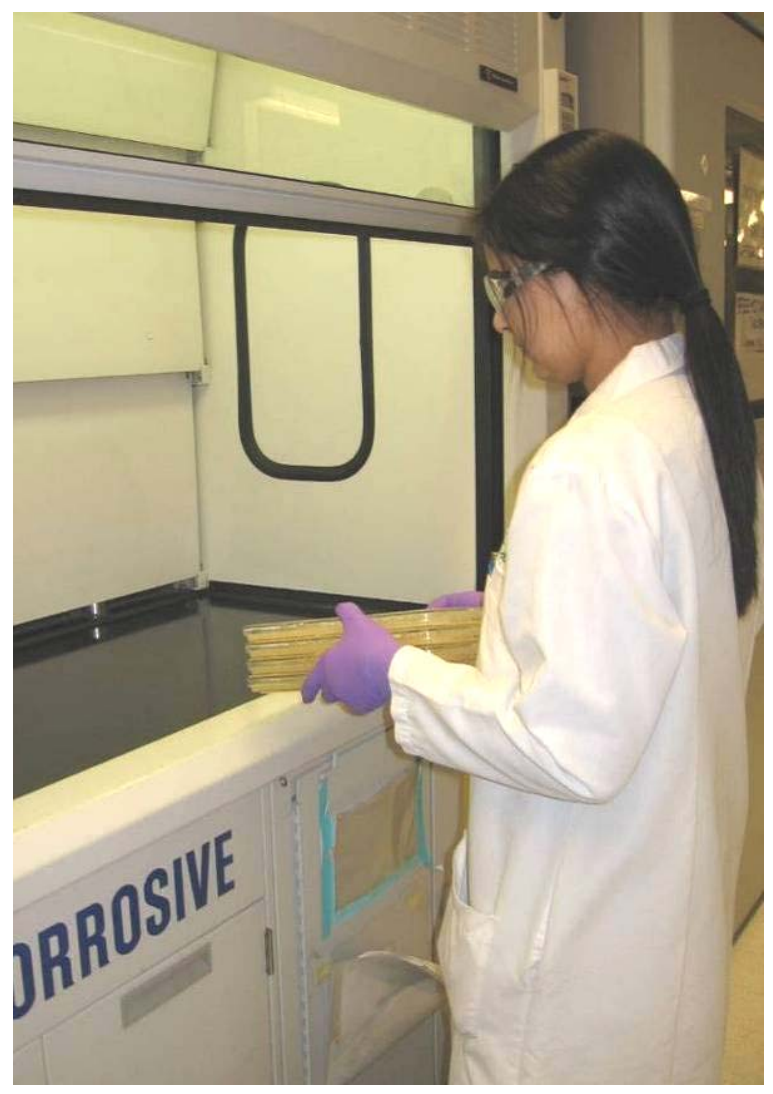

Before

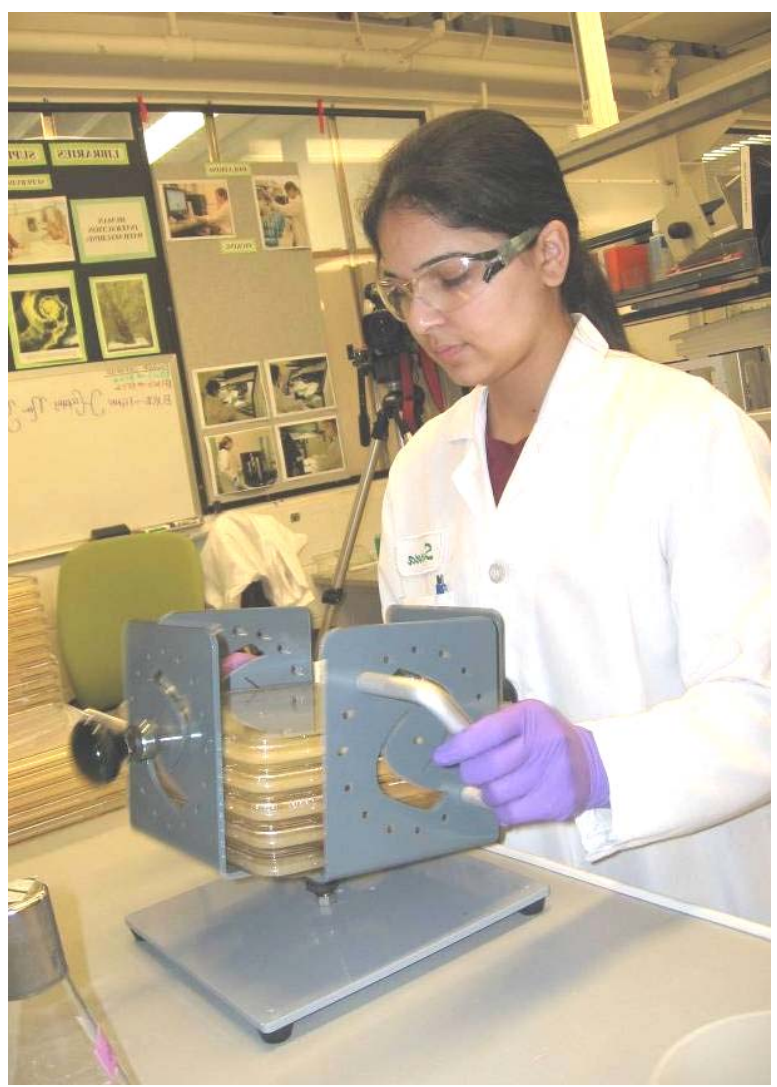

After
Administrative:

- Leg Room for seated option Off the Shelf:

- Lighter plates

-Anti-fatigue Mat

Engineering (custom):

-Fixture to hold the plates

Increased Productivity:

$\cdot 25 \% \uparrow$ throughput 


\section{Outcome}

\begin{tabular}{|l|l|}
\hline Safety & $\begin{array}{l}\bullet \text { Grip Force } 14-19 \% \text { of maximum voluntary contraction } \\
\bullet \text { Moore-Garg Strain Index }=2.3\end{array}$ \\
\hline Quality & $\bullet$ The quality of the sample did not change. \\
\hline Delivery/Efficiency & $\begin{array}{l}\bullet \text { Process } 5 \text { bioassays per cycle with fixture. } \\
\bullet \text { Increased throughput by } 25 \% .\end{array}$ \\
\hline Cost & $\begin{array}{l}\bullet \text { Reduction in process time by } 25 \% \\
\bullet \text { ROI }(10 \text { years) }=0.6 \text { months } \\
- \text { Since the intervention, production staff reports no discomfort after } \\
\text { plating, and no injuries have occurred in association with this task. }\end{array}$ \\
\hline Morale/Teamwork & $\begin{array}{l}\bullet \text { Participatory process } \rightarrow \text { production staff design concept. } \\
\bullet \text { The new workstations } \uparrow \text { flexibility for multiple operators. } \\
- \text { Increased morale due to improvement of task and potential for } \\
\text { future automation \& cross training. }\end{array}$ \\
\hline
\end{tabular}




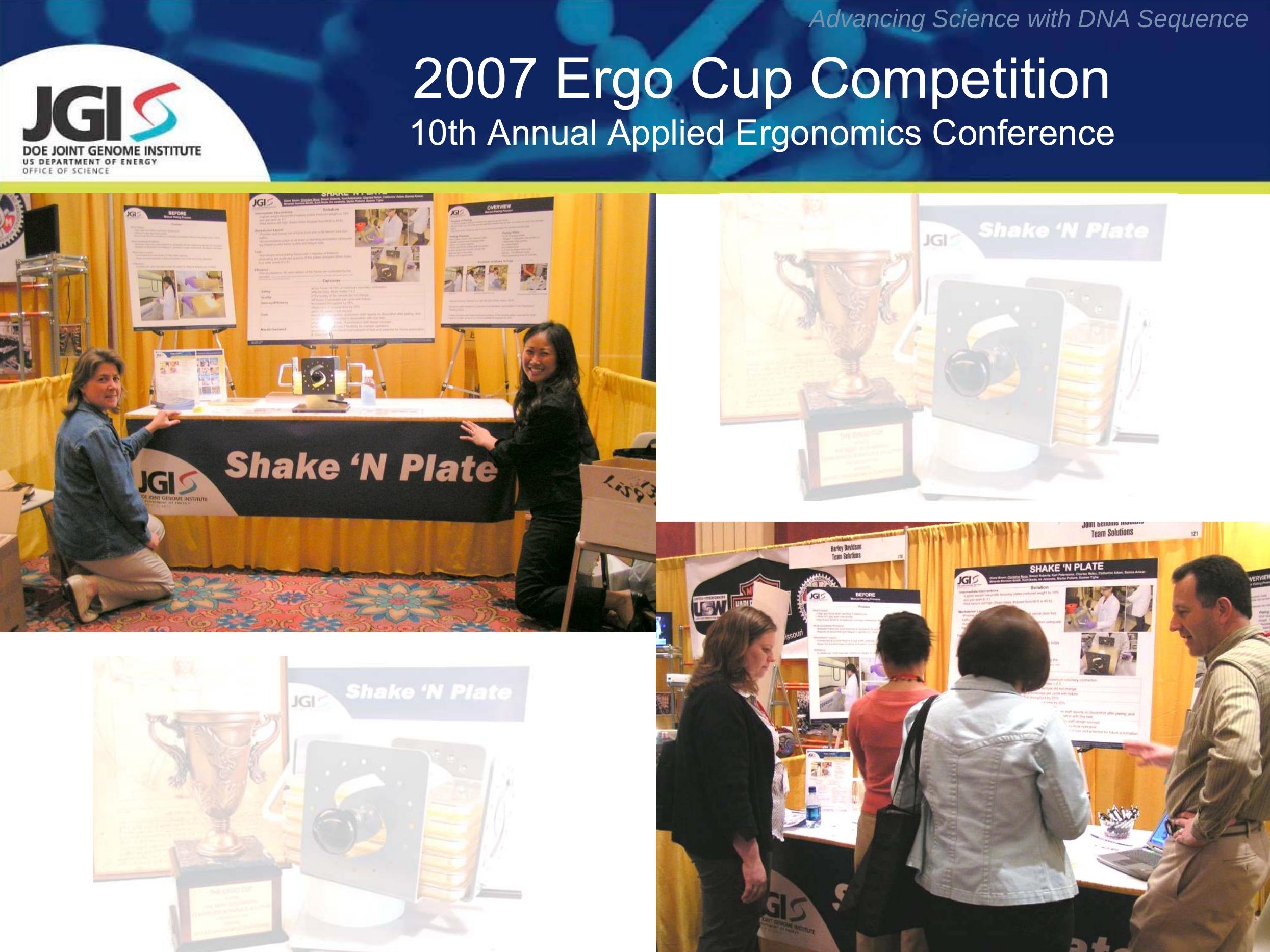




\section{Ergo Cup Winners \\ "Team Driven Workplace Solutions"}

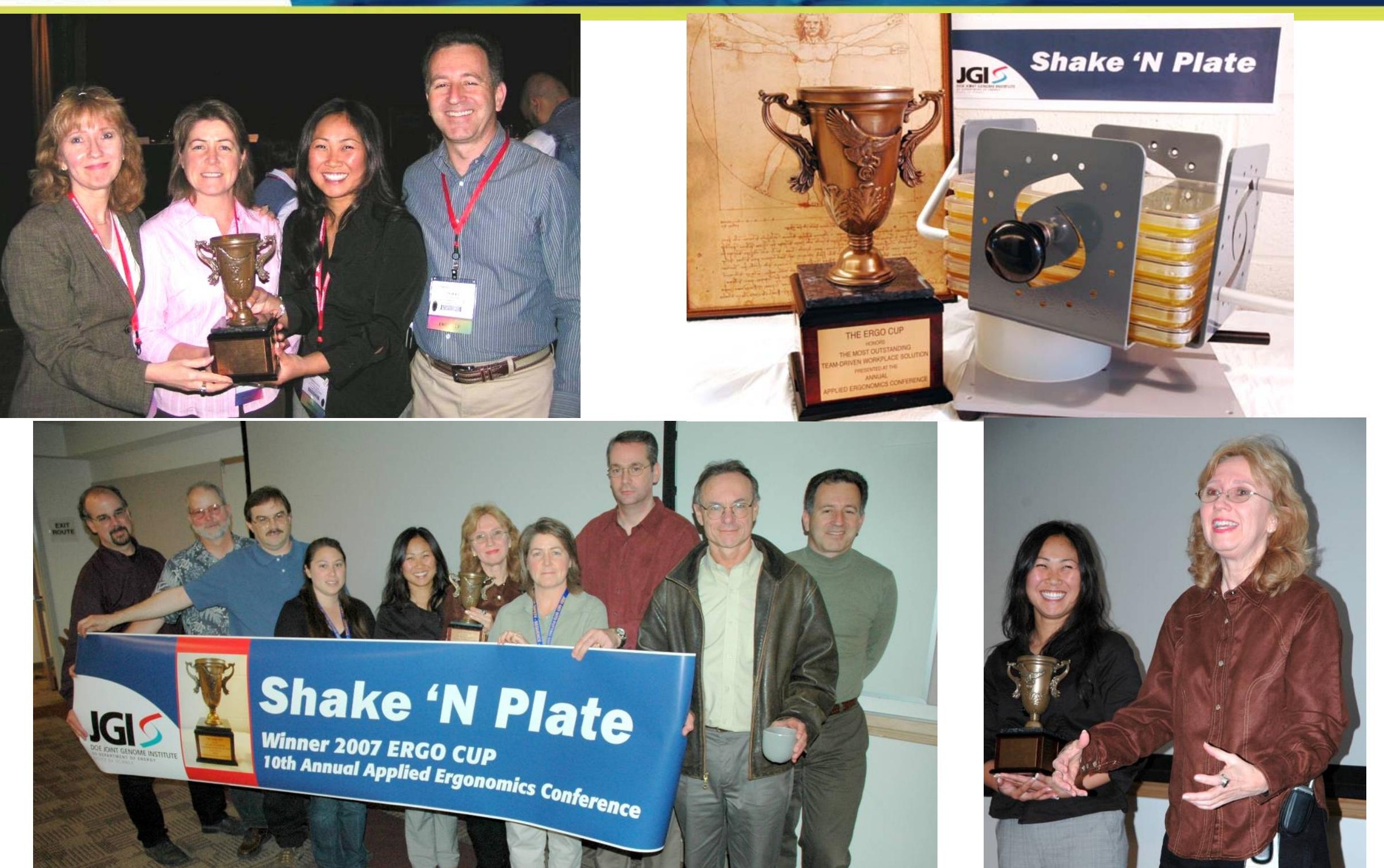




\section{Evolution of Shake "N Plate}

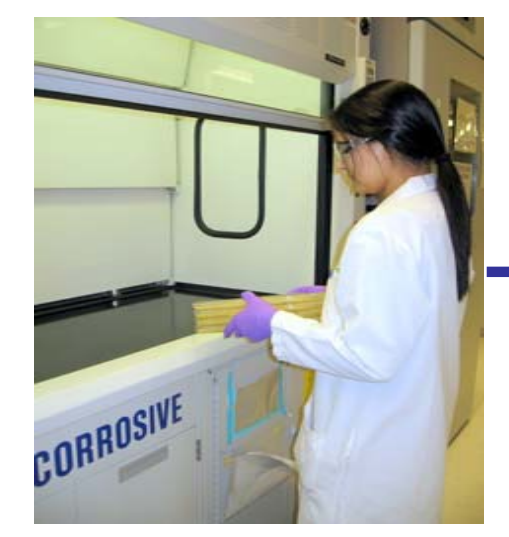

BEFORE

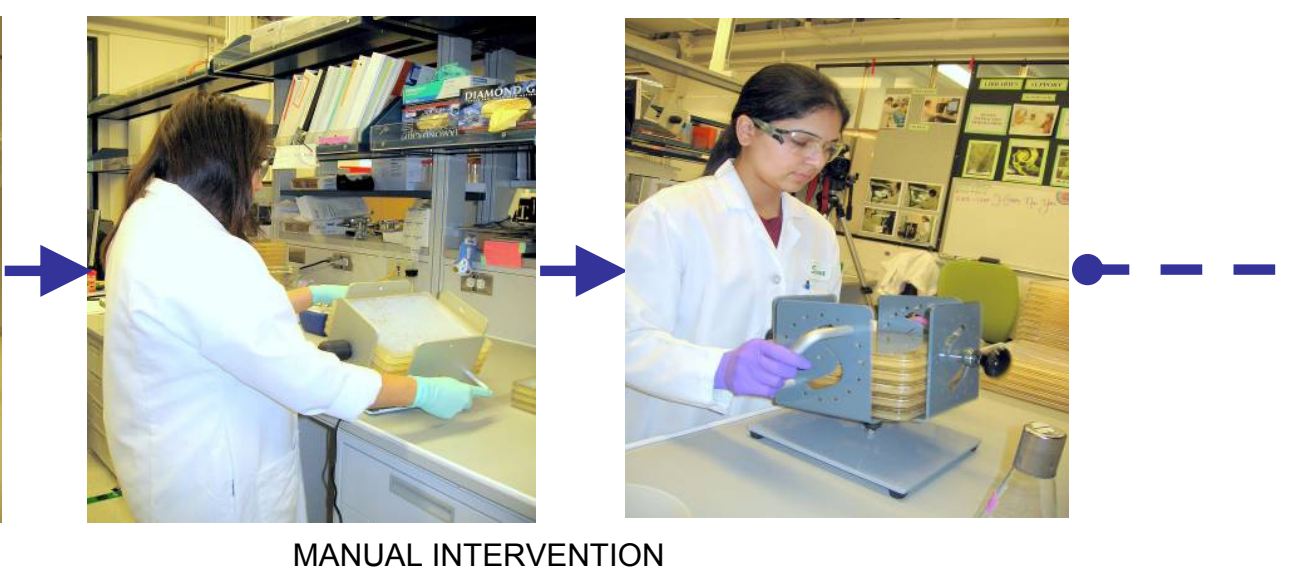

MANUAL INTERVENTION

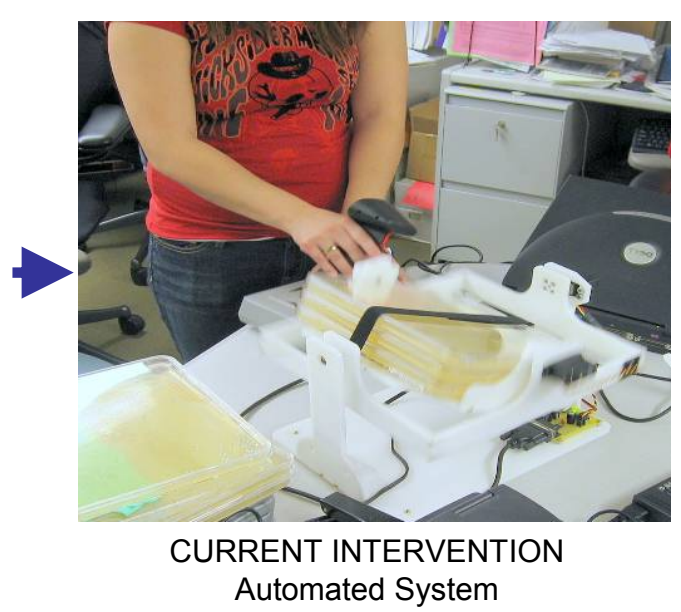




\section{The JGI Ergo Program Why Are We Having Success?}

- Teamwork

- Employee-led Ergonomics Working Group

- Management Commitment

- Identify Solutions

- Quick Fix-Administrative Solutions

- Long Term-Engineering Solutions

- On-Site Ergo Support

- Rapid Response

- Encourage Early Reporting

- Communication/Education

- Group Meetings

- Posters

- Weekly Ergo Email

- Custom Ergo Training Courses 


\section{Managing Ergonomics Team Effort}

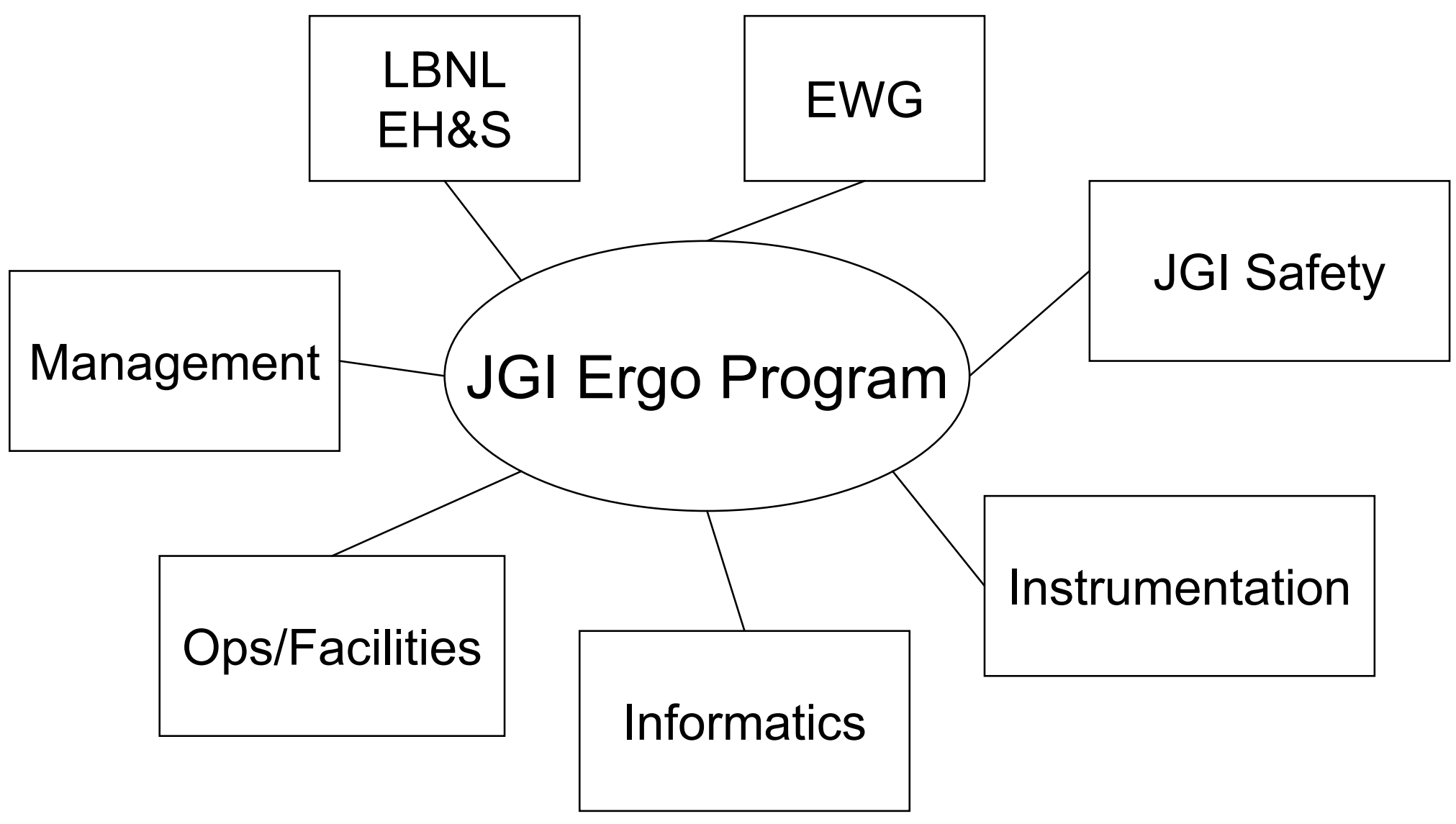




\section{Engaging the Staff}

\section{Ergonomics Working Group}

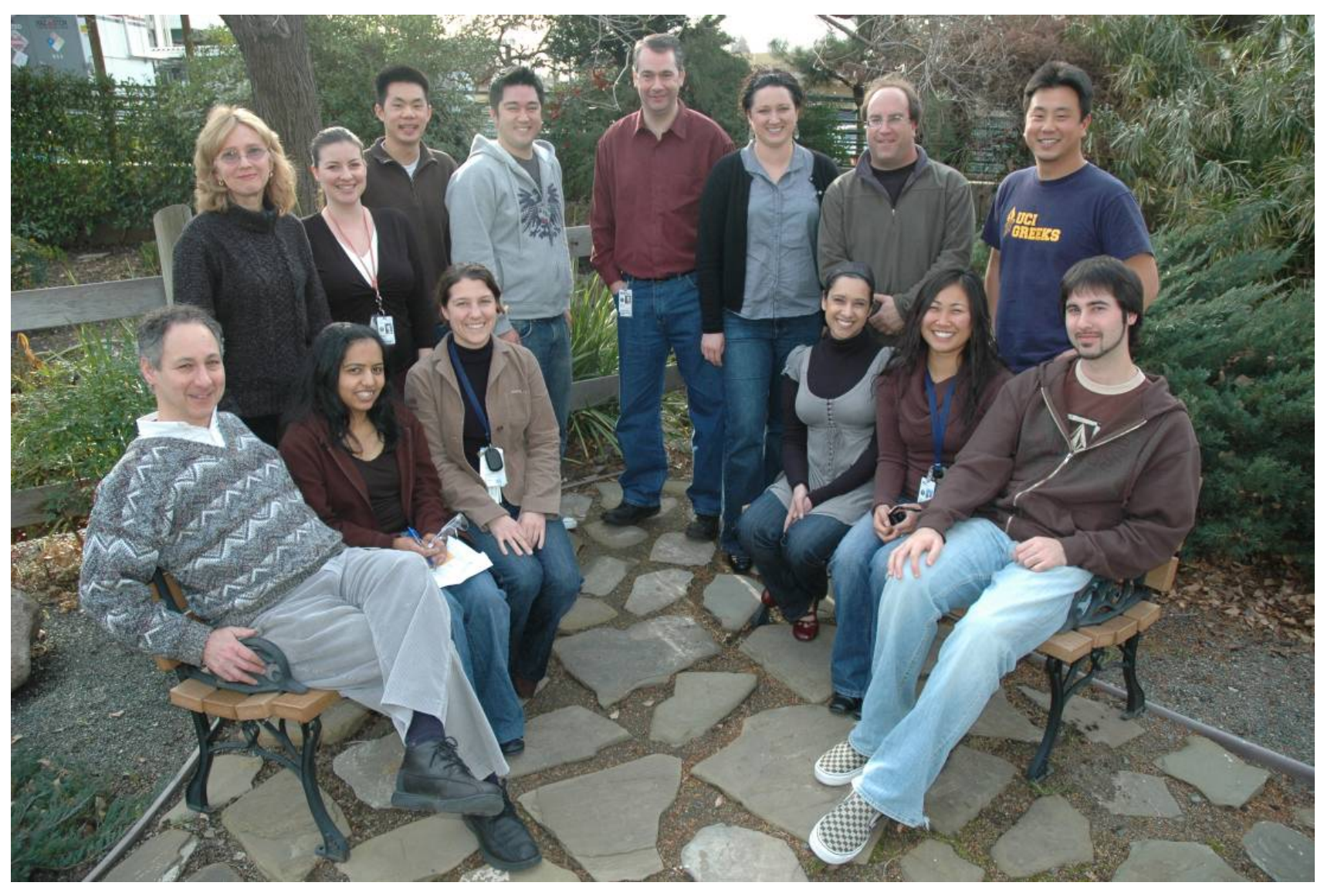




\section{Current Ergo Project Status}

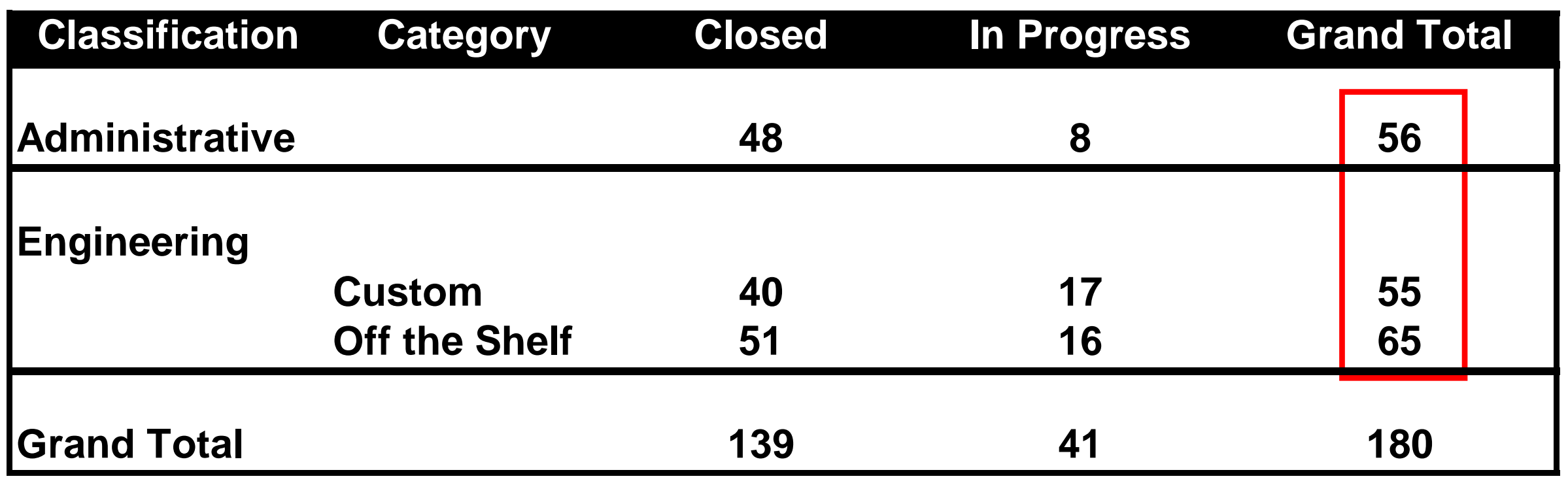

\# Ergo Projects by Classification 


\section{Communication and Education}

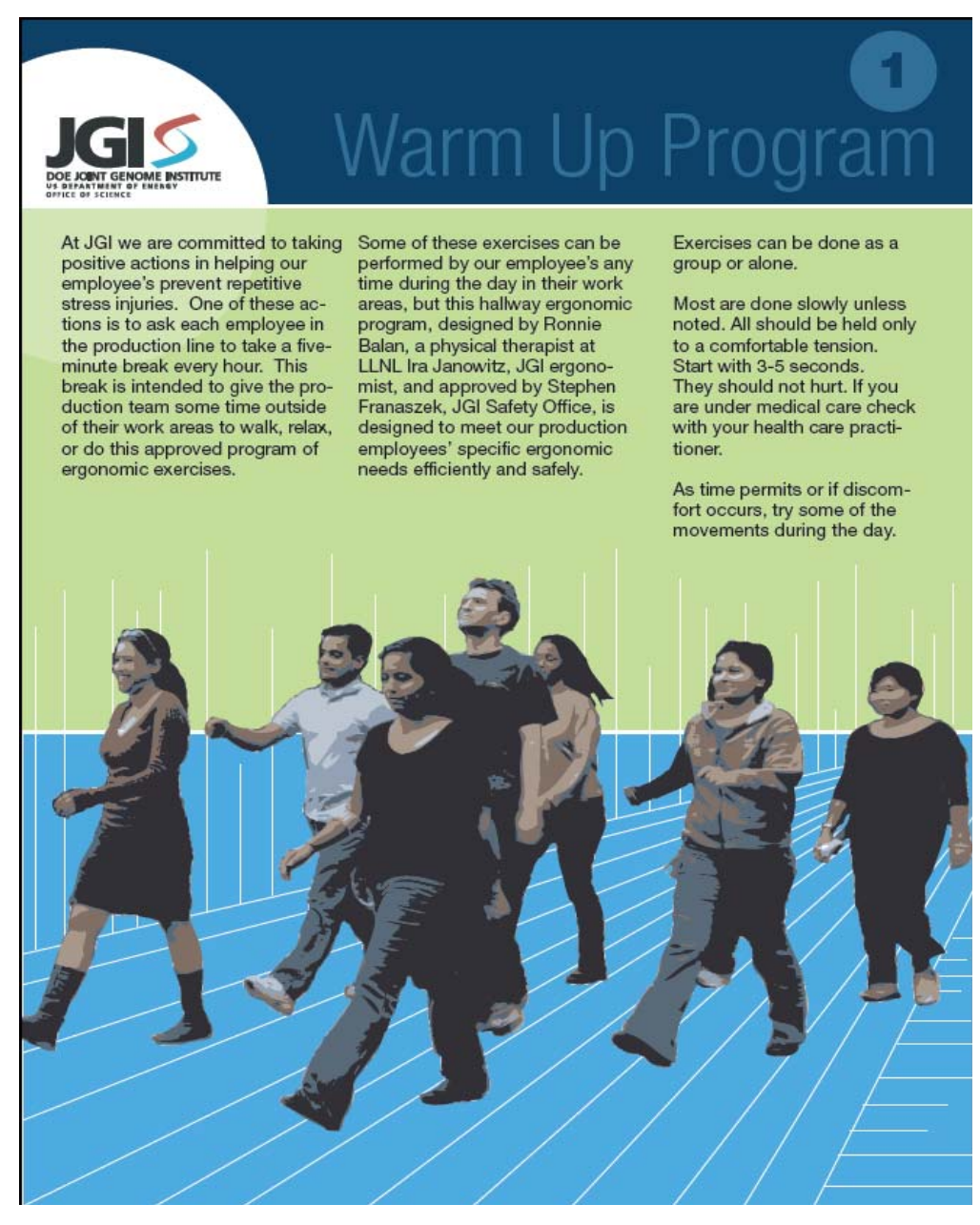

Stretch Posters

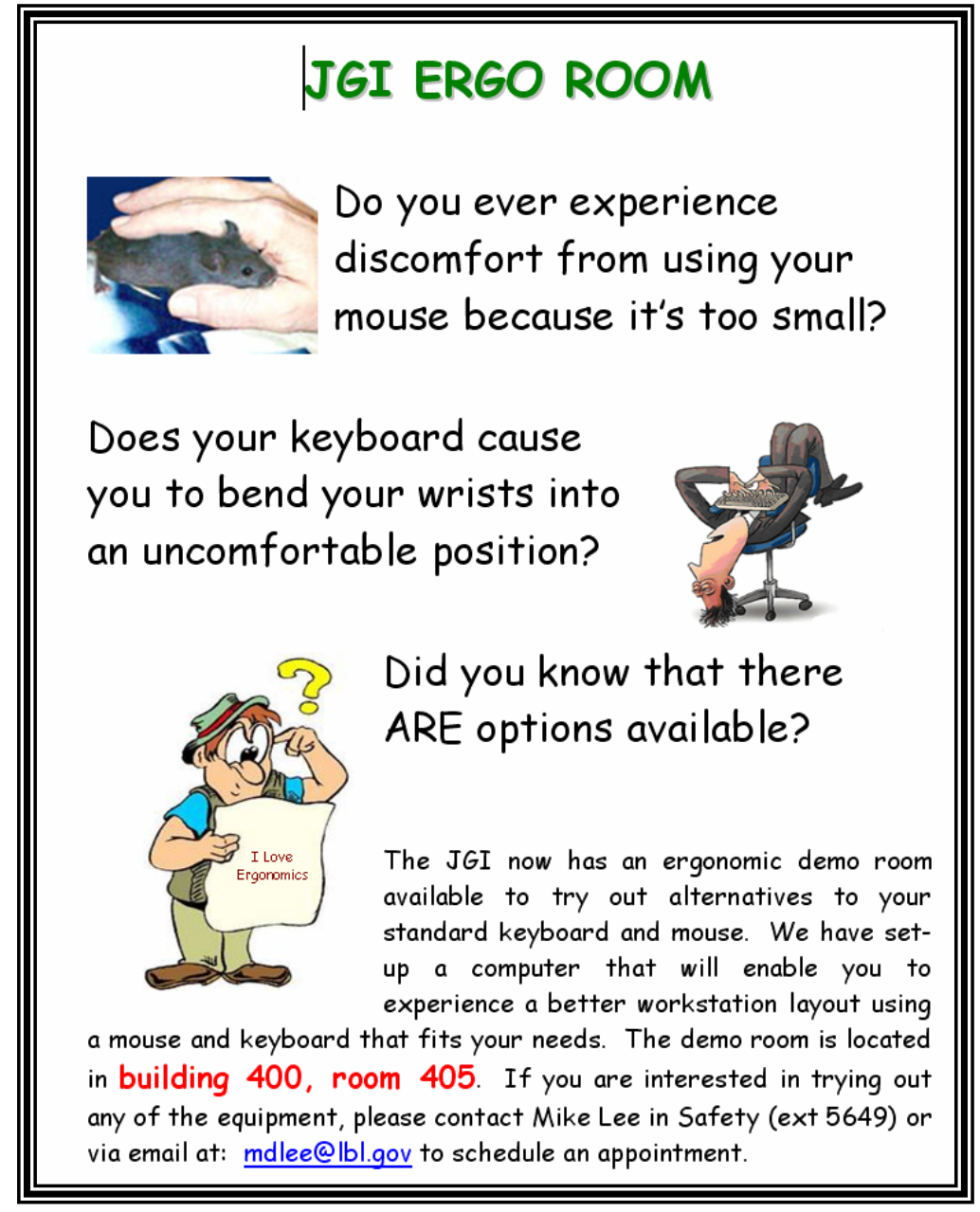

Potty Training 

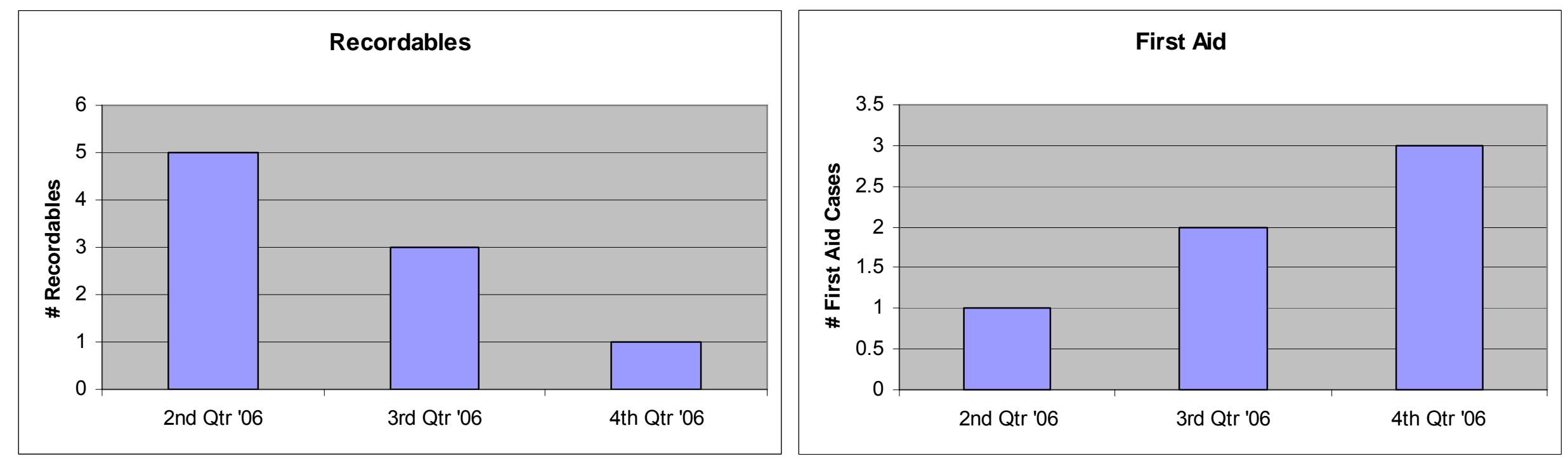


\section{Challenges}

- Equipment/instruments designed for small batches/small lab use now being used for high throughput operation

- Culture:

- Understanding Efficiency vs. Speed

- Regular Breaks and Lunch

- Mix of hand-intensive activities

- Overtime practices

- Staffing issues 


\section{In Summary}

- Collaborative Effort

- Continuous Improvement

- Proactive and Participatory Ergonomics Program

Results:

- Improved Employee Morale

- Decreased Recordable Injuries

-Winner of 2007 Ergo Cup for "Team Driven Workplace Solutions" 
This work was performed under the auspices of the US Department of Energy's Office of Science, Biological and Environmental Research Program, and by the University of California, Lawrence Livermore National Laboratory under Contract No. W-7405-Eng-48, Lawrence Berkeley National Laboratory under contract No. DEAC02-05CH11231 and Los Alamos National Laboratory under contract No. DEAC02-06NA25396.

Project Team: Diane Bauer, Christine Naca, Simon Roberts, Karl Petermann, Charles Reiter, Catherine Adam, Sanna Anwar, Miranda Harmon-Smith, Karli Ikeda, Ira Janowitz, Martin Pollard, Damon Tighe 